International Journal of Forensic Science \& Pathology (IJFP)

ISSN 2332-287X

\title{
Forensic scientific evidence: problems and pitfalls in India
}

V.R.Dinkar

\begin{abstract}
Forensic science, the sibling of science has transformed the criminal adjudication especially the criminal trial process. There is no doubt about the role of forensic science in helping the judiciary in settling issues which are outside the ken of judges. However, nowadays forensic scientists as well as the stakeholders in the legal community are facing serious criticisms from different levels regarding its reliability and the capability of the legal community to screen it. Several problems and pitfalls are there which directly affect the trustworthiness of the forensic science. It starts from the very initial stage of crime scene investigation and continues up to the stage of trial. In the legal setting, the major problem is the difference in between the scientific and legal community concerning the sphere of interaction. It is high time to find out the real problems and to correct it unless it would result in serious miscarriage of justice.
\end{abstract}

Keywords: Forensic scientific evidence; Chain of custody; Individualization; Reliability; Admissibility.

\section{*Corresponding Author:}

V.R.Dinkar LL.M., Ph.D.,

Associate Professor \& Dean, VIT Law School, VIT University,

Chennai. India.

Tel: 9003163464

E-mail: dinkar.vr@vit.ac.in

Recieved: January 06, 2015

Accepted: February 03, 2015

Published: February 09, 2015

Citation: V.R.Dinkar (2015) Forensic Scientific Evidence: Problems and Pitfalls in India. Int J Forensic Sci Pathol. 3(2), 79-84. doi: http://dx.doi. org/10.19070/2332-287X-1500020

Copyright: V.R.Dinkar ${ }^{\circ}$ 2015. This is an open-access article distributed under the terms of the Creative Commons Attribution License, which permits unrestricted use, distribution and reproduction in any medium, provided the original author and source are credited.

\section{Introduction}

Forensic science, the sibling of science has transformed the criminal adjudication especially the criminal trial process. Nowadays, it has become a greater helping hand of the crime investigation agencies and the criminal justice system in properly identifying the guilty and safeguarding the innocent. In a recent case, Dharam Deo Yadav v. State of U.P. [1], the Supreme Court of India has explained the importance of forensic scientific evidence, particularly in more brutal and well organized crimes. The potentiality of scientific evidence in criminal investigation and trial is undisputed but the role of the legal stakeholders and their capability in screening the evidence is always a controversial topic not only in India but also throughout the globe. In India, it is also doubtful whether the criminal investigation team is fully equipped to grab the culprit without using third degree methods. Moreover, the most alarming thing is the reporting of some erroneous convictions as a result of faulty forensic evidence [2-5]. To date around 318 convicts who were convicted with faulty forensic evidences were released from jail on the basis of DNA test. The purpose of the paper is to highlight some of the major shortcomings in our system concerning forensic scientific evidence and to bring out some suggestions for improvement.

\section{Problems Associated with Crime Scene Investiga- tion and Chain of Custody}

Crime Scene Investigation (hereinafter CSI) is the significant and opening procedure in all criminal cases. The importance of CSI was observed by the Supreme Court in Yadav's case:

... [F]orensic science plays a pivotal role, which may assist in establishing the element of crime, identifying the suspect, ascertaining the guilt or innocence of the accused. One of the major activities of the Investigating officer at the crime scene is to make thorough search for potential evidence that have probative value in the crime. Investigating Officer may be guarded against potential contamination of physical evidence which can grow at the crime scene during collection, packing and forwarding. Proper precaution has to be taken to preserve evidence and also against any attempt to tamper with the material or causing any contamination or damage [1].

It is a widely accepted fact that the quality of the evidence based on forensic procedures depends mainly on the quantity and quality of the forensic samples collected from the crime scene. Therefore, utmost care should be given by the investigators while handling the crime scenes [6]. In a criminal trial, the weight of the evidence is determined on the basis of strength of the chain of custody of the forensic evidence starting from the stage of 
first reporting by the police personnel who had visited the crime scene. Regrettably, due to the mistakes from the side of the police authorities in India, the probative value of the evidence will be affected when it comes for trial. There are various factors that directly affect the value of the real evidence. The most important one is the ignorance of the investigating officers in handling the crime scene and the way in which they collect the evidence from the scene. Due to the lack of education and training, the police personnel's usually disturb the crime scene and destroy the valuable evidence which could be collected intact by a trained Crime Scene Investigator with his due diligence and skill.

For establishing an accurate chain of custody, there should be a proper communication of information from the first person who visits the crime scene to the police investigators and crime scene investigators. Everything considered as having link with the crime should be photographed, video recorded and properly documented. Systematic documentation is essential to establish the credibility of the scientific evidence. In India, unfortunately neither the investigating officers nor the judiciary give much of importance to the chain of custody.

The other major problem which affects the forensic evidence is the way in which the investigating authorities are handling the crime scene. This is obviously due to their lack of knowledge in crime scene investigation. Similar to the U.S. or U.K. in India there is no criminalistics. The police will directly enter into the scene and disturb and taint the valuable evidences. The feasible solution is that if the police personnel's feel unmanageable the crime scene, they should request to the concerned FSL to have a detailed investigation. The more serious concern is the possibility of purposeful contamination of the crime scene materials to save the culprit from the liability. This usually happens either due to the bribery or because of high political influence.

\section{Autonomy of Crime Labs}

In India the most serious concern is about the independence of crime labs and its self regulation. The state and central forensic science laboratories are under the direct administrative control of the law enforcement authorities. The State and Union Territory Forensic Science Laboratories is either directly functioning under the respective Home Department or through police establishments. The Central Bureau of Investigation has a separate forensic science laboratory at Delhi with a branch at Chennai [7]. In the U.S., the National Academy of Sciences in its report, "Strengthening Forensic Science in the United States: A Path Forward" (hereinafter NAS Report) has observed: "The best science is conducted in a scientific setting as opposed to a law enforcement setting. Because forensic scientists often are driven in their work by a need to answer a particular question related to the issues of a particular case, they sometimes face pressure to sacrifice appropriate methodology for the sake of expediency" [8]. The forensic personnel's are always pressurized by the law enforcement wing which results in faulty forensic analysis and results. In the NAS report it is stated that bias is there in all crime laboratories [9-12]. The main reason for the bias is because of the organizational structure of the crime labs [13]. Currently, the crime laboratory personnel's feel that they are working under the police department for convicting the accused, hence bias. This could be solved to a great extent if the forensic experts change their mindset and think that they are 'good scientists than good prosecution witnesses'. The prosecutor also influences the scientific experts and changes their mind for winning his case [13]. The usual procedure is that before the examination, he will tutor the scientific witness for creating a proper link of evidence. Nowadays, scientists identified cognitive bias as a problem in the subjective decision making of forensic scientists. This is more serious in forensic identifications like fingerprint, footprint, hair etc, in which conclusions are reached through subjective judgment [14].

\section{Partisanship of Forensic Experts}

The term 'partisanship' in this context means favoring the party who is paying for the expertise [15-16]. In criminal cases, forensic personnel's are salaried government servants whose duty is to help the state in establishing the truth. Apart from their salary they are not expected to accept any remuneration from any other person for the case in which they are duty bound to serve the state. In most of the cases the partisanship happens because of two reasons: (1) if an expert is hired by a person for stating opinion only favorable to the party and for that he will form his own theory and come as witness to convince the judge about the application of his theory through which the party could succeed; [17] (2) an expert who is a government servant after accepting bribe from the opposite side will create twist or submit wrong statement with manipulated forensic reports. Some experts are named as "hired guns", who will prepare for the party who hired him. This is like selling their opinion for the party who are ready to purchase them [17]. In fact, partisanship and bias are two sides of the same coin because if partisanship is present then there is possibility of bias. The reason is that if an expert is remunerated by a party, obviously that expert shall always be biased towards the other side.

Forensic scientific experts are educated, trained, experienced and skilled persons. Their duty is to testify the truth they discovered through the application of their special knowledge which cannot be detected by the judges using their commonsense. At this juncture, I think it is not productive to suggest for a better expertise through the system in which the experts will function in a well defined ethical code; instead, I would like to advice for a complete separation of expert opinion epistemology from the present organizational structure to the province of the judiciary. This can be effectively done either through 'court appointed experts' or 'panel of experts'. The court appointed or panel experts can check the partisanship if any on the side of any of the experts representing the parties and restrict the faulty evidence entering into the courtroom.

\section{Problems Relating To 'Individualization'}

Individualization is a process through which forensic science discerns a person or thing from the rest of others in the world. It is, in fact, the power of forensic science and without this utility it has lesser significance in the legal system [18]. Only through this individualization process forensic experts can declare a perfect match of the crime scene material with the crime, accused or victim. However, all these determinations are based on probabilistic calculations since in proof no one can expect any mathematical certainty. The major query at this juncture is how much of individuality could be gained from forensic application. In fact, the recent research studies has pointed out that even the concept 'individualization' itself is a fallacy. Michael J. Saks \& Jonathan J. Koehler has rightly mentioned in their paper that unique individuality cannot be proven with limited samples ([19], p209). That 
means if we want to know that a particular characteristic of a person or thing is really unique, it is logically impossible without checking the rest of the things or persons. For example, the well accepted hypothesis that no two fingers in the world have same ridge characteristics will be refuted by the discovery of similar ridge characteristics of two fingers. If that happens what would be the future of the fingerprint evidence.

The way in which the reports of the forensic analysis are communicated to the judiciary is very important. The strength and weight of forensic evidence depends on the probabilistic calculations. In India the forensic scientific evidence is flowing into the courtroom in an incomplete nature. It is an accepted fact in both forensic and legal community that if the evidence is not communicating to the courtroom in the form of probabilistic calculations, it is worthless since it is the only way in which the scientists can properly convey it to others. Unfortunately, in India the scientific experts are submitting their reports stating only whether the samples are matching or not. This, in fact, is not sufficient to check the probative value of the evidence because with this form of evidence it is difficult to determine the individuality excluding others having the possibility of similar characteristics. The probative value of a particular piece of evidence always depends on its strength to exclude the possible suspects other than the accused. In the legal setting, the probative value of particular forensic evidence is useful not only to prove a particular fact in issue of a case but also to disprove it. For e.g., if a DNA sample collected from the crime scene match the sample from the suspect, it has probative value to connect the suspect with the crime. On the other hand, if it mismatches, it will exclude the suspect from the crime ([20], p37).

A forensic scientific expert cannot simply come before a court of law and testify in an untestable manner that two objects or persons that involved in a crime are same. They are responsible to adduce statistics in a quantifiable manner, so as to distinguish the similarities and differences of the two. This doesn't mean that the expert should search the entire objects in that class before reaching the conclusion that the object in issue is unique. The advantage of quantitative data is that it would be easier for the expert to communicate his subjective as well as objective findings before the fact finder. The other merit is that the fact finder can easily make a link with other form of evidence.

\section{Factors Affecting the Reliability of Forensic Sci- entific Evidence in India}

In India, though forensic science is considered as a reliable discipline, there are various pertinent factors, apart from those discussed earlier, which affects the reliability of case specific application of the technique. The list includes

1. lack of scientific certainty

2. lack of research

3. forensic science as neglected discipline

4. absence of well defined code of ethics

5. lack of certification to the technical personnel's

6. lack of national database for identification evidence

7. lack of error rate statistics for all techniques, and so on.

The lack of scientific certainty in forensic science is not only the problem in India but also it is a common problem throughout the world. Different from other scientific disciplines, in forensic science there is no absolute scientific proof or certainty. The major reason is because of its close association with law since in legal truth finding different from scientific, law is not expecting any certainty but the proof based on probabilities. As Craig rightly stated, "public crime laboratories are not sanctuaries of science...." ([21], p442). The public cannot give that much of reliance on those labs similar to other research laboratories because in crime labs the scientists are researching with old, degraded, partial, distorted, blurred and contaminated samples. Similarly, all forensic identification tests based on matching of samples are based on the subjective evaluation of the examiner which is subject to the final interpretation by an independent person. Because of the human intervention, there is possibility of error in fixing the match of different characteristics in two samples.

The other major problem affecting the reliability is the lack of research and the shortage of peer-reviewed papers and validation studies. Moreover, the applications of the majority of forensic techniques are based on long standing application in the court of law and not as a result of proper scientific research. The best example is fingerprint technique which has no valid scientific basis, though considered as reliable by the judiciary due to its long standing track record [22].

The National Research Council of the National Academies, United States, in its publication "Strengthening Forensic Science in the United States: A Path Forward" has made certain valuable recommendations for improving the accuracy, reliability and validity in the forensic science disciplines. The recommendations are:

"The National Institute of Forensic Science should competitively fund peer-reviewed research in the following areas:

a. Studies establishing the scientific bases demonstrating the validity of forensic methods.

b. The development and establishment of quantifiable measures of the reliability and accuracy of forensic techniques should reflect actual practice on realistic case scenarios, averaged across a representative sample of forensic sciences and laboratories. Studies also should establish the limits of reliability and accuracy that analytic methods can be expected to achieve as the conditions of forensic evidence vary. The research by which measures of reliability and accuracy are determined should be peer reviewed and published in respected scientific journal.

c. The development of quantifiable measures of uncertainty in the conclusions of forensic analyses.

d. Automated techniques capable of enhancing forensic technologies" [23].

Apart from the aforesaid problems, in comparison with other scientific disciplines, forensic science is always treated as a neglected discipline. From very early days most of the nations have sidelined it as a part of law enforcement and justice delivery system. This was the reason for the shortage of funding from the government for research.

The bias, bribe and partisanship of experts are escalating due to the absence of well defined code of ethics and its proper implementation. Restrictions should be imposed by the state against experts in offering the services to the defense. For all forensic techniques stringent protocol should be implemented to over- 
come bias. In India also we have to formulate a code of ethics and proper mechanism for enforcing it. In the U.S., The National Institute of Forensic Science (NIFS) has recommended that there should be a national code of ethics for all forensic science disciplines and encourages individual societies to incorporate this national code as part of their professional code of ethics [23]. It also emphasizes that a proper mechanism should be established to enforce the code for those who commit serious ethical violations [23].

The other well-known challenge is the quality assurance in forensic service. The quality of the evidence depends on several factors like validation of a technique, instrumental quality check, capacity of the persons employed, standard protocol, and accreditation of the crime labs and certification of the scientists. If there is compromise in any of these factors, it will directly affect the quality and there by the reliability of test results. Apart from this, the overall quality can be tested using proficiency tests. The proficiency tests are useful for testing both scientific personnel and crime lab. The test can be conducted by a national body like NIFS in U.S. or National Accreditation Board for Testing and Calibration Laboratories (NABL) in India ([24], pp.295 - 300).

\section{Forensic Science in the Criminal Justice System}

In the earlier discussions we saw several problems and pitfalls in the forensic scientific discipline that affects the reliability of the evidence. Now it is right time to turn our discussion to the legal scenario. In criminal cases, the forensic scientific evidence enters into the legal arena through the prosecutors (as prosecution's evidence) and defense (defense evidence). Once it enters into the witness box, different stakeholders will be handling it before it transforms into the level of proof. In this part, for better understanding about the problems, discussions are arranged in the order of different stakeholders through whom the scientific evidence translates into proof. As a rule, in all criminal cases, the case will be opened by the prosecutor. His burden is heavier than the defense. Though the prosecutor is appearing for the state, unlike private parties, he is not having any fiduciary relationship with the state. His role is rather distinguishable from his adversary. The duty of the prosecutor is not only to convict the real culprit but also to save the innocent persons from erroneous convictions and thereby to prevent serious miscarriage of justice. This is sine qua non for strengthening the criminal justice administration based on the strong pillars of rule of law. Unfortunately, in India, what is observable in prosecutions is that majority of the prosecutors are hastened to jump into the conclusion of guilt of the accused regardless whether he has in fact committed the offence. This, in fact, is more tear-jerking than callous crimes.

The screening of the forensic scientific evidence should start from the prosecutor. Forensic personnel's inside the while coat may come with biased and fallacious scientific reports yarned with scientific jargons. The role of the prosecutor is to spot out the trap so as to save the system and to uphold the public morale on it. He has to schoolwork the report before it enters into the corridors of the court of law. Regrettably, in India, it is little bit shocking to say that the prosecutors neither apply their mind into the wording of the report nor take any effort to find out the flaws in it. The most appalling obsession is that quite few manipulators will thoroughly tutor their scientific witnesses in order to conceal certain major flaws in the report. The brilliant prosecutors are well aware that if any flaws intrude into the bunch of evidence, the defence will take the benefit of doubt.

\section{What is Lacking in India Regarding the Screening of Fo- rensic Evidence}

Unlike prosecution, the defence lawyer has the duty to save his client and there is a fiduciary relationship. Due to the rapid development of second generation forensic scientific techniques like DNA typing, brain mapping, cyber forensics and the rest, the task of the defense lawyers and judges has increased enormously in screening the evidence. At bottom, the fundamental thing to be achieved by both scientific and the legal community is to achieve truth, however, the way in which it should be achieved is different. In fact, the role of science and technology in the legal landscape is to help the legal system in achieving truth through its application. The major difficulty that constantly arises due to this application is the overburdening of the lawyers and judges in evaluating the scientific evidence. Nowadays, in some cases, courtrooms are becoming real scientific laboratories and judges and lawyers as amateur scientists.

Comparison of Indian courts with other jurisdictions, especially U.S. and U.K. would shed light on the bare truth that the Indian judges don't have that much of confidence to base conviction solely on the basis of scientific evidence since they are not in a position to fix its reliability up to their satisfaction. In most of the cases in which the evidence based on forensic science comes before the court of law seeking admission, courts were used to follow 'corroboration' as a rule of prudence for conviction and it will be on the basis of the association of that evidence with some other independent piece of evidence in the case. Like other jurisdictions, in India, there is no specific standard either fixed by law or guidelines of the Supreme Court for evaluating scientific evidence. In the United States, Daubert v. Merrell Dow Pharmaceuticals, Inc., [25] is the first landmark case in which U.S. Supreme Court gave proper guidelines for evaluating scientific expert evidence. This was again clarified by the court in Kumbo Tire Co. v. Carmichael. [26]. In Daubert the court entrusted the trial court judges with the responsibility of gatekeepers of scientific evidence. In Kumbo, the Supreme Court extended this gate-keeping function to all expert evidence regardless of scientific or nonscientific. In Daubert court laid down a comprehensive checklist for evaluating scientific expert evidence:

1. whether it can be tested;

2. whether the theory or technique has been subjected to peer review and publication;

3. the known or potential error rate; and

4. general acceptance of the technique in the relevant scientific community.

In fact, the above mentioned checklist helps judges in determining whether the proffered scientific evidence is sufficiently reliable enough for admissibility. Apart from this Daubert court has also stated that "Vigorous cross-examination, presentation of contrary evidence, and careful instruction on the burden of proof are the traditional and appropriate means of attacking shaky but 
admissible evidence." The Kumbo court's clarification regarding the application of the Daubert checklist factors to nonscientific expert testimony apparently created confusion in forensic science, since some of the major forensic techniques are not strictly coming under the science. Even though some problems are there in the admissibility of scientific expert evidence in the U.S., the law is somewhat lucent than other jurisdictions.

In India, conversely, the law is silent regarding the determination of the reliability and thereby the admissibility of scientific expert evidence. Section 45 of the Indian Evidence Act, 1872 simply says that if a person has some special skill on a particular subject like science or art, he may be called as an expert and his evidence is a relevant fact. Similarly, section 51 approves the relevancy of the grounds of an expert's opinion. Apart from this, there is no rule that guides the trial judge in determining the reliability and admissibility of expert evidence.

The major tension created in the mind of evidence scholars in India is the possibility of admitting expert evidence at face value due to the ignorance of the judges in understanding the premises on which a particular expert evidence gyrates. In most of the jurisdictions especially in the U.S. it is almost accepted that the judges has to screen the scientific evidence to exclude junk science ([27], p715). But it seems like a mockery since the lay judges without having any scientific background could really isolate the wheat from the chaff.

Whatever general standards and checklist we lay down for the evaluation of the reliability of forensic scientific evidence, it is the responsibility of the trial judge alone to fix it in the case at hand after considering the propositions and its application to the existing facts. In India, there is no jury trial; the judge is the sole person to determinate the legal as well as factual issues. Therefore, judges should educate themselves in different forensic scientific techniques and it is also submitted that in India it is high time to provide the reference materials to the judges on novel forensic scientific evidences similar to the U.S. "Federal Judicial Center's Reference Manual on Scientific Evidence", [28] which gives judges speedy reference of high-tech evidences that comes before them.

Apart from the judicial training on forensic scientific evidence, continuing education for judges and lawyers is also helpful to a great extent in educating them. However, if there is conflicting opinions from the side of the experts of both parties, the judge would be in confusion regarding the determination of the admissibility of the theory and methodology of different experts. To overcome such situation, it is wise to appoint court - appointed - experts ([29] p473). This is also useful to evaluate biased, partisan and misleading expert testimony. In such situations, it is not necessary that the testimony of the court - appointed - experts should be subjected to cross examination since he is not related to both parties. In India, it is also feasible to constitute an "Expert Jury Trial System" to help judges to resolve complex scientific testimony. Expert Jury Trial consists of juries who are experts on the concerned scientific evidence so that they can easily evaluate the reliability of the proffered scientific evidence.

It is also advisable that in India, the Bar Council of India should take immediate necessary steps to add forensic science and medical jurisprudence as courses along with other law courses espe- cially for the students who are planning to practice in the criminal side. For the practicing lawyers, concerned Bar Associations may offer special training programmes in forensic science and medical jurisprudence, which would be useful for enriching their knowledge.

\section{Conclusion}

I hope this short journey through different problems and pitfalls in the application of forensic science has generated enough pleasure to the readers for an in depth study on the application of the discipline in the Indian legal system. The message, I would like to convey to my readers is that bad apples are there in all disciplines; so the ultimate job of the judiciary should be a routine monitoring of the system so as to make the personnel's involved in it accountable and thereby improve the quality of the services. In India, it is also high time to enact a special legislation similar to the Forensic Procedures Act in Australia, to deal with the entire matters of forensic science.

\section{References}

[1]. (2014) SCc_509 hypothetical protein [ Serratia symbiotica str. 'Cinara cedri' ], Gene ID: 11576315: http://www.ncbi.nlm.nih.gov/gene?term=scc\%20 509[gene]\%20AND\%20alive[prop]\%20NOT\%20newentry[gene] \%20 \&sort=weight

[2]. Jane Campbell Moriarty (2007) "Misconvictions," science, and the ministers of justice. Neb. L. Rev. 86: 1.

[3]. William C. Thompson (2008) Beyond bad apples: analyzing the role of forensic science in wrongful convictions. Sw. U. L. Rev. 37: 1027.

[4]. Jennifer L. Mnookin (2008) Excerpt from transcript of proceedings: experts and forensic evidence. Sw. U. L. Rev. 37: 1009.

[5]. Brandon J. Garrett, Peter J (2009) Neufeld. Invalid forensic science testimony and wrongful convictions. Va. L. Rev. 95: 1.

[6]. Fisher, B. A., \& Fisher, D. R. (2012). Techniques of crime scene investigation. CRC Press.

[7]. Dr. Gopal Ji Misra, Dr. C.Damodaran (2010) The final report on perspective plan for Indian forensics. available at http://www.mha.nic.in/hindi/sites/ upload_files/mhahindi/files/pdf/IFS\%282010\%29-FinalRpt.pdf.

[8]. United States of America, National Research Council (2009) Strengthening Forensic Science in the United States: A Path Forward, 328.

[9]. Paul C. Giannelli (2008) The abuse of scientific evidence in criminal cases: the need for independent crime laboratories, Va. J. Soc. Pol'y \& L4. 439.

[10]. Andre A. Moenssens (1993) Novel scientific evidence in criminal cases: some words of caution. J. Crim. L. \& Criminology. 84: 1.

[11]. Randolph N. Jonakait (1991) Forensic science: the need for regulation. Harv. J.L. \& Tech.4:109.

[12]. James E. Starrs (1993) The seamy side of forensic science: the mephitic stain of Fred Salem Zain. Sci. Sleuthing Rev.17: 1.

[13]. Paul C. Giannelli (2010) Independent crime laboratories: the problem of motivational and cognitive bias. Utah L. Rev. 247.

[14]. Jonathan J. Koehler, John Meixner (2011) Northwestern University School of Law: Final Report.Workshop on cognitive bias and forensic science. 7

[15]. Ronald J. Allen, Joseph S. Miller (1993) The common law theory of experts: deference or education?. Nw. U. L. Rev. 87: 1131.

[16]. Jennifer L (2001) Mnookin. Scripting expertise: the history of handwriting identification evidence and the judicial construction of reliability. Va. L. Rev. 87: 1723 .

[17]. Jennifer L (2007) Mnookin. Idealizing science and demonizing experts: an intellectual history of expert evidence. Villa. L. Rev. 52: 763.

[18]. David L. Faigman (2008-2009) Modern scientific evidence: the law and science of expert testimony, 34:1.

[19]. Michael J. Saks, Jonathan J (2008) The individualization fallacy in forensic science evidence. Vand. L. Rev. 61: 199.

[20]. Tom Mcewen (2010) National Institute of Justice Office of Justice Programmes U.S. Department of Justice. The role and impact of forensic evidence in the criminal justice system.

[21]. Craig M. Cooley (2011) Nurturing forensic science: how appropriate funding and government oversight can further strengthen the forensic science community. Tex. Wesleyan L. Rev. 17: 441.

[22]. P.C. Giannelli (2001) Scientific evidence in civil and criminal cases. Ariz. St. L. J.103: 112. 
[23]. National Academy of Sciences (2009) Strengthening forensic science in the United States: a path forward. The National Academies Press; Washington, D.C, 190.

[24]. V.R.Dinkar (2013) Scientific expert evidence: determining probative value and admissibility in the courtroom. Eastern Law House.

[25]. Sanders, J., Diamond, S. S., \& Vidmar, N. (2002). Legal perceptions of science and expert knowledge. Psychology, Public Policy, and Law, 8(2), 139.

[26]. Kumho Tire Co. v. Carmichael (1999) is a United States Supreme Court case that applied the Daubert standardto expert testimony from nonscientists. (2nd Edtn) 143: 238.
[27]. Bert Black (1994) Science and the law in the wake of daubert: a new search for scientific knowledge. Tex. L. Rev. 72.

[28]. Federal Judicial Center. National Research Council. Reference manual on scientific evidence. 3rd ed. The National Academies Press; Washington D.C. https://www.supremecourt.ohio.gov/LegalResources/LawLibrary/resources/ scientificEvidence.pdf

[29]. Jack B. Weinstein (1986) Improving expert testimony. U. Richmond L. Rev. 204. 